\title{
Erratum to: Assessment of nitrogen and phosphate balance and the roles of bacteria and viruses at the water-sediment interface in the Allal El Fassi reservoir (Morocco)
}

Mohamed Alaoui-Mhamdi • Amel Dhib •

Abderrahim Bouhaddioui • Boutheina Ziadi • Souad Turki • Lotfi Aleya

Published online: 27 September 2014

(C) Springer International Publishing Switzerland 2014

Erratum to: Environ Monit Assess, (2014) 186:5817-5829

DOI 10.1007/s10661-014-3821-7

The original version of this article unfortunately contained a mistake.

The Fig. 1 at left and below lacks the Moroccan Sahara.

The correct figure is shown here.

The online version of the original article can be found at http//:dx.doi. org/10.1007/s10661-014-3821-7.

M. Alaoui-Mhamdi $\cdot$ A. Bouhaddioui

Faculté des Sciences Dhar Mehrez, Département de Biologie,

B.P. 1796 Fès, Morocco

A. Dhib · B. Ziadi $\cdot$ L. Aleya $(\bowtie)$

Laboratoire Chrono-Environnement, UMR CNRS 6249, La

Bouloie, Université de Franche-Comté,

Avenue de l'Observatoire, Besançon, France

e-mail: lotfi.aleya@univ-fcomte.fr

A. Dhib $\cdot$ B. Ziadi $\cdot$ S. Turki

Laboratoire Milieu Marin, Institut National des Sciences et

Technologies de la Mer (INSTM),

Centre la Goulette, Salammbô, Tunisia 


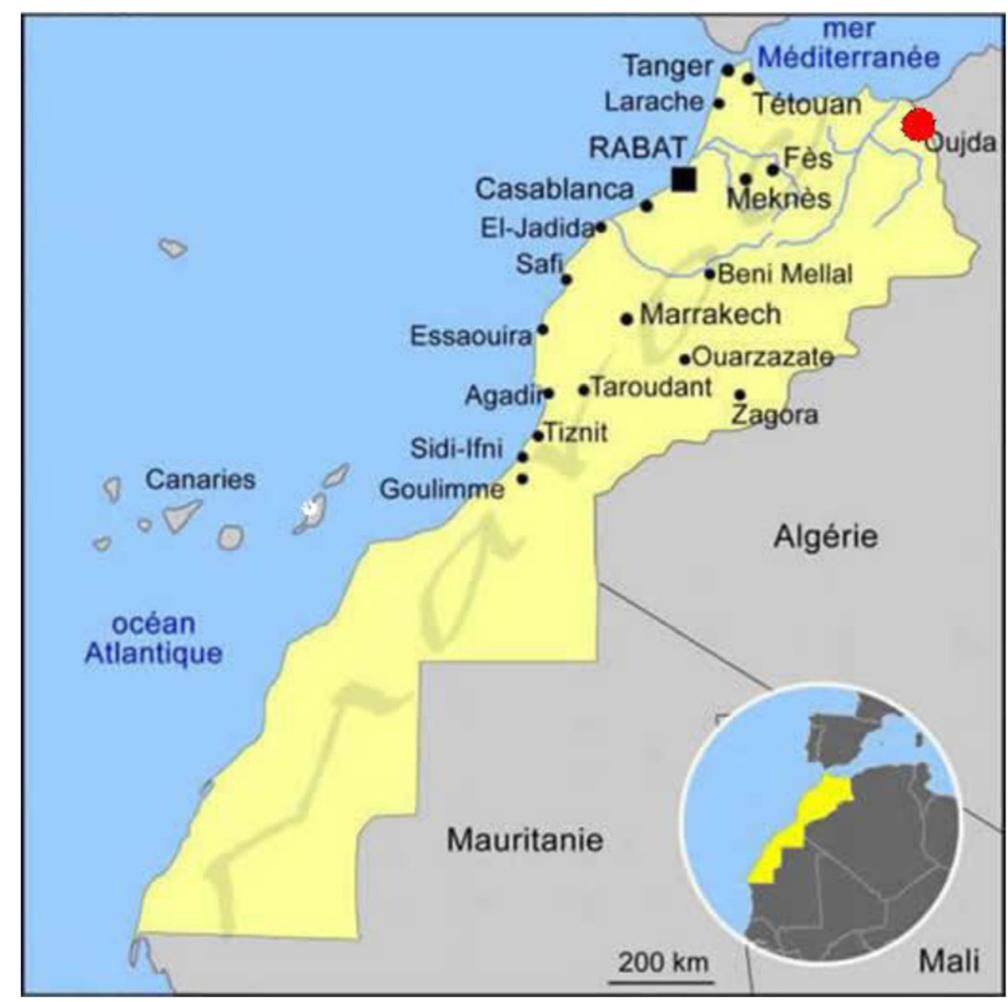

